UDC 551.3.053

LBC 26.32

\title{
CARTOGRAPHIC PROVISION OF MONITORING OF ENGINEERING-GEOLOGICAL PROCESSES ON THE BASIS OF GIS-TECHNOLOGIES
}

\author{
Mikhail A. Shubin \\ Volgograd State University, Volgograd, Russian Federation
}

\begin{abstract}
Mapping information is needed when using geo-information technologies to develop a system of monitoring geological processes. The thematic basis of the engineering-geological map is a data Bank for assessing the state of the geological environment. The sources of the digital cartographic basis are remote sensing data and field survey materials. The data is included in the contents of the MapInfo working set. Engineering-geologic map consists of two thematic layers. The first layer - stratigraphic genetic complexes of surface deposits, their composition and physical and mechanical properties. The second layer is a characteristic of exogenous processes, including a description of the types, prevalence (scale) and intensity of manifestation separately for each group of processes: landslide, erosion, Aeolian, suffusion-karst, waterlogging and flooding. As an example, the map of soil density in MapInfo for the pipeline section is shown.
\end{abstract}

Key words: engineering-geological map, monitoring, geo-information system, MapInfo.

УДК 551.3.053

ББК 26.32

\section{КАРТОГРАФИЧЕСКОЕ ОБЕСПЕЧЕНИЕ МОНИТОРИНГА ИНЖЕНЕРНО-ГЕОЛОГИЧЕСКИХ ПРОЦЕССОВ НА ОСНОВЕ ГИС-ТЕХНОЛОГИЙ}

\author{
Михаил Алексеевич Шубин \\ Волгоградский государственный университет, г. Волгоград, Российская Федерация
}

\begin{abstract}
Аннотация. Картографическая информация необходима при использовании геоинформационных технологий для разработки системы литомониторинга геологических процессов. Тематической основой инженерно-геологической карты является банк данных для оценки состояния геологической среды. Источниками цифровой картографической основы служат данные дистанционного зондирования и материалы полевых съемок. Данные включаются в содержание рабочего набора карты MapInfo. Инженерно-геологическая карта включает два тематических слоя. Первый слой - стратиграфо-генетические комплексы поверхностных отложений, их состав и физико-механические свойства. Второй слой - характеристика экзогенных процессов, включающая описание типов, распространенности (масштаба) и интенсивности проявления отдельно для каждой группы процессов: оползневых, эрозионных, эоловых, суффозионно-карстовых, заболачивания и подтопления. В качестве примера показана карта плотности грунтов в MapInfo для участка газопровода.

Ключевые слова: инженерно-геологическая карта, мониторинг, геоинформационная система, MapInfo.

Картографическое обеспечение создает научно-методическую и информационную основу для формирования баз и банков геологической информации о состоянии природной среды, для создания геоинформационных си-

стем и принятия управленческих и проектных решений $[1,2,5-8]$.

Реализация оценки параметров природной среды для разработки системы литомониторинга включает:
\end{abstract}


М.А. Шубин. Картографическое обеспечение мониторинга инженерно-геологических процессов

- создание фонда базовой картографической информации, содержащего различные карты, составленные на основе имеющихся к началу наблюдений материалов;

- сбор, обработку и систематизацию оперативных данных аэрокосмических и наземных наблюдений для их картографирования;

- перевод обработанных данных в картографическую форму: составление оперативных карт развития инженерно-геологических процессов, условий их распространения и происходящих при этом изменений геологической среды;

- анализ составленных карт с целью выявления закономерностей распространения наблюдаемых явлений, оценки и прогноза их развития.

Источниками создания цифровой картографической основы могут служить данные дистанционного зондирования (аэро- и космические снимки), материалы полевых съемок, в том числе полученные с помощью систем спутникового позиционирования $[4,15,19,22]$.

Картографический банк данных для оценки состояния геологической среды по исследуемому объекту должен представлять серию инвентаризационных, оценочных и прогнозных карт.
В качестве тематической основы большинства карт следует использовать инженерно-геологическую карту [11-13], которая является базовой для серии карт, отображающих:

- различные техногенные воздействия на состояние геологической среды в процессе добычи, переработки и транспортирования полезных ископаемых;

- инженерно-геологические процессы, происходящие в зоне воздействия технических объектов;

- техногенные изменения структуры, состояния и свойств грунтов;

- прогноз развития геологических процессов.

Инженерно-геологические карты должны обеспечивать комплексную характеристику инженерно-геологических условий района исследования, включая геологическое строение, гидрогеологические условия, состав, состояние и свойства грунтов, инженерно-геологические процессы, изменение условий освоенных (застроенных) территорий, составление прогноза возможных изменений инженерно-геологических условий в сфере взаимодействия технических объектов с геологической средой $[14,17,18,21]$. Содержание рабочего набора карты, в частности, для трассы газопровода, характеризуется табл.1,2.

Таблийа 1

Описание содержания рабочего набора (карты MapInfo)

\begin{tabular}{|l|l|l|}
\hline $\begin{array}{c}\text { Имя таблицы } \\
\text { МapInfo } \\
\text { (слоя карты) }\end{array}$ & \multicolumn{1}{|c|}{ Описание } & Характер локализации \\
\hline GAS & Трубопроводный коллектор (собственно трасса) & Линии и полигоны \\
\hline BUFFER & Граница земельного отвода & Полигоны \\
\hline GIDRO & Гидрографическая сеть & Линии и полигоны \\
\hline GEOLOG & $\begin{array}{l}\text { Стратиграфо-генетические комплексы поверхно- } \\
\text { стных отложений }\end{array}$ & Полигоны \\
\hline GIDROGEOL & Гидрогеологические условия & Линии \\
\hline
\end{tabular}

Таблииа 2

Описание структуры таблицы GEOLOG

\begin{tabular}{|l|l|l|}
\hline \multicolumn{1}{|c|}{ Имя поля } & \multicolumn{1}{|c|}{ Описание } & \multicolumn{1}{|c|}{ Тип данных } \\
\hline FKOBJCODE & Код объекта & Словарь \\
\hline FKLAYER1 & Состав субстратов & Словарь \\
\hline SUBSTRATUMTHICK & Мощность субстратов & Вещественное \\
\hline BIOGENTHICK & $\begin{array}{l}\text { Мощность современных отложений, } \\
\text { залегающих на коренных породах }\end{array}$ & Вещественное \\
\hline FKLAYER2 & $\begin{array}{l}\text { Название, генезис и состав второго от } \\
\text { поверхности комплекса отложений }\end{array}$ & Словарь \\
\hline FKGEOLPROCESSES & Современные геологические процессы & Словарь \\
\hline NOTE & Примечание & \\
\hline
\end{tabular}




\section{ГЕОГРАФИЯ И ГЕОИНФОРМАТИКА}

Инженерно-геологическая карта включает два тематических слоя - стратиграфо-генетических комплексов поверхностных отложений, их состав и физико-механические свойства. Соответственно, слой стратиграфо-генетических комплексов поверхностных отложений отражает следующие их характеристики (табл.3).

В частности, для характеристики физико-механических свойств грунтов используется следующее описание (табл.4)

В качестве примера карты, составленной в соответствии с данной структурой таблицы в MapInfo, приводится карта плотности грунтов для участка газопровода (рис.1).

Таблица 3

Описание инженерно-геологической карты

\begin{tabular}{|l|l|l|}
\hline $\begin{array}{c}\text { Имя таб. (слоя) } \\
\text { MapInfo }\end{array}$ & \multicolumn{1}{|c|}{ Описание } & Тип объектов \\
\hline GEOLOG & $\begin{array}{l}\text { Стратиграфо-генетические комплексы } \\
\text { поверхностных отложений }\end{array}$ & Полигоны \\
\hline FMCHARACT & Физико-механические характеристики & Полигоны \\
\hline GIDROGEOL & Гидрогеологические условия & Полилинии \\
\hline
\end{tabular}

Описание структуры таблицы FMCHARACT

Таблииа 4

\begin{tabular}{|l|l|l|}
\hline \multicolumn{1}{|c|}{ Имя поля } & \multicolumn{1}{c|}{ Описание } & \multicolumn{1}{c|}{ Тип данных } \\
\hline FMOBJCODE & Код объекта & Словарь \\
\hline DENSITY & Плотность & Вещественное \\
\hline DEFORMATION & Модуль деформации & Вещественное \\
\hline RESISTSHIFT & Сопротивление сдвигу & Вещественное \\
\hline RESISTCOMPRESS & Сопротивление сжатию & Вещественное \\
\hline NOTE & Примечание & \\
\hline
\end{tabular}

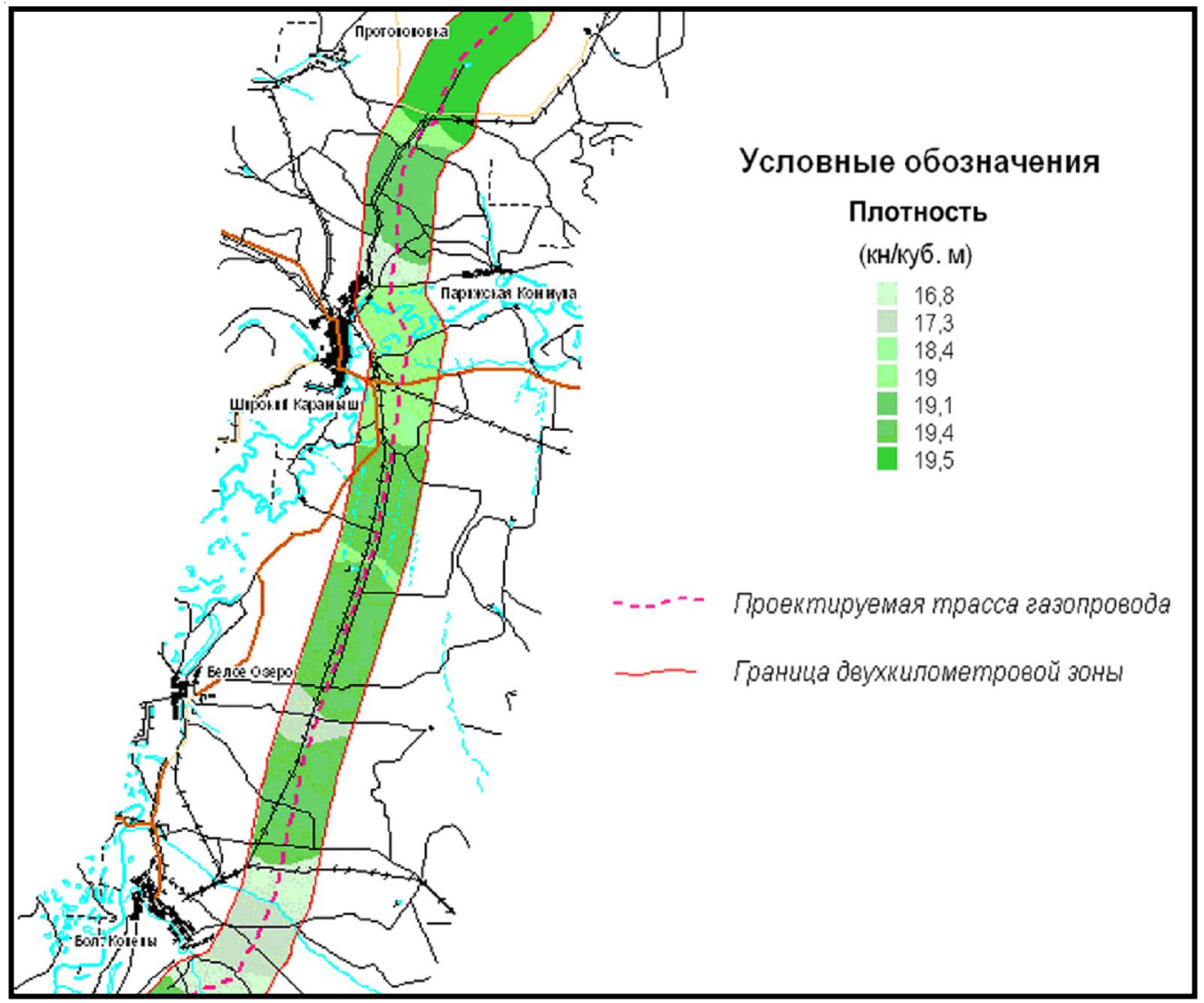

Рис. 1. Карта плотности грунтов для участка газопровода 
Характеристика экзогенных процессов включает описание типов, распространенности (масштаба) и интенсивности проявления и строится отдельно для каждой группы процессов: оползневых, эрозионных, эоловых, суффозионно-карстовых, заболачивания и подтопления (табл.5).

Картографическое обеспечение мониторинга инженерно-геологических процессов проводилось в зоне газопровода ПочинкиИзобильное-Северо-Ставропольское ПХГ и в значительной мере помогло выполнить анализ факторов и динамики развития этих процессов $[3,6,9,10,16,20]$.

Без современных информационных технологий такой анализ потребовал бы обработки значительного объема традиционной статистической и картографической информации.

Таким образом, применение ГИС-технологии мониторинга инженерно-геологических процессов позволяет не только хранить и визуализировать данные наблюдений, но и устанавливать связи между факторами и процессами, выявлять тенденции их развития и принимать управляющие решения на основе прогнозных оценок.

\section{СПИСОК ЛИТЕРАТУРЫ}

1. Берлянт А.М. Геоинформационное картографирование/ А.М. Берлянт// Картография и геоинформатика. Итоги науки и техники. Сер. Картография. - М.: ВИНИТИ АН СССР, 1991. - Т. 14. C. $80-117$.

2. Иванцова, Е.А. Компьютерное картографирование сохранности зеленых насаждений в городских ландшафтах / Е.А. Иванцова, Р.В. Овсянкин // Известия Нижневолжского агроуниверситетского комплекса: наука и высшее профессиональное образование. - 2016. - № 2 (40). - С. 119-127.

3. Макаров, В.3. Применение ГИС-технологий при оценке факторов природного риска на нефтяных месторождениях Нижнего Повол- жья / В.З. Макаров // ГИС-обозрение. - 2004. №3. - С. 89-98.

4. Невечеря, В.Л. Информационное инженерно-геологическое обеспечение мониторинга сложных природно-технических систем (на примере газовых промыслов в криолитозоне) / В.Л. Невечеря // Инженерная геология. - №1 . 1992. - C. 82-90.

5. Сербенюк, С.Н. Картография и геоинформатика - их взаимодействие / С.Н. Сербенюк - М., 1990. -159 c.

6. Старцев Ю.П., Разработка геоинформационной системы литомониторинга газотранспортного комплекса / Ю.П. Старцев, М.А. Шубин // Вузовская наука - региону: сб. мат-лов 3-й Всеросс. науч.-тех. конф. - Вологда, 2005. - С. 75-82.

7. Шайтура, С.В. Геоинформационные системы и методы их создания / С.В. Шайтура - Калуга: Изд-во Н. Бочкаревой, 1998. - 252 с.

8. Шахраманьян, М.А. Новые информационные технологии в задачах обеспечения национальной безопасности России (природно-техногенные аспекты). Монография. / М.А. Шахраманьян - М., ФЦВНИИ ГОЧС, 2003. - 398 c.

9. Шеко, А.И. Временное прогнозирование экзогенных геологических процессов / А.И. Шеко, В.С. Круподеров//Гидрогеология. Инженерная геология и строительные материалы: докл. сов. геологов. - М.: Наука, 1980. - С. 188-193.

10. Шеко, А.И. Оценка опасности и риска экзогенных геологических процессов / А.И. Шеко, В.С. Круподеров // Инженерная геология. - № 3.1994. - C. 11-21.

11. Ширяев, Е.Е. Картографическое отображение, преобразование и анализ геоинформации / Е.Е. Ширяев - М.: Недра, 1989. - 248 с.

12. Шубин, М.А. Методологические основы программирования литомониторинга / М.А. Шубин // Инженерная геология. - 1987. - № 6. - С. 74-86.

13. Шубин, М.А. Литомониторинг: теоретические и прикладные аспекты / М.А. Шубин - Волгоград: Принт, 2005. - 276 с.

14. Шубин, М.А. Проблемы экологической безопасности прибрежных городских территорий Волгоградского водохранилища / М.А. Шубин, О.В. Юшин//Антропогенная трансформация гео-

\section{Описание структуры таблицы EXOGEN}

\begin{tabular}{|l|l|l|}
\hline \multicolumn{1}{|c|}{ Имя поля } & \multicolumn{1}{|c|}{ Описание } & \multicolumn{1}{c|}{ Тип данных } \\
\hline FKOBJCODE & Код объекта & Словарь \\
\hline FKTYPE & Тип процесса или явления & Словарь \\
\hline FKLOKALIZATION & Характер распространения & Словарь \\
\hline FKEXGENESIS & Происхождение & Словарь \\
\hline FKINTENSITY & Интенсивность проявления в ландшафтах & Словарь \\
\hline NOTE & Примечание & Символьное \\
\hline
\end{tabular}

Таблийа 5 
пространства: история и современность.- Волгоград: Изд-во ВолГУ, 2015. - С. 416-422.

15. Clarce, K.C. Geographic information systems: definitions and prospects/ K.C. Clarce// Bull. Geogr. and Map Div. Spec. Libr. Assoc. - 1985. - № 142. pp. 12-17.

16. Ferguson, E. A technical and operational comparison of geographic information systems as applied to the Canada forest industry / E.Ferguson Vancouver: FRDA, 1989. - 20 p.

17. GIS'89 Vancouver, Symposium proceedings "A Wider Perspective", march 7-10 1989, Vancouver, Canada, 1989. - 243 p.

18. National Workshop on Geographical Information System, Second, Proceedings. Beijing'90, 8-11 august. Beijing: LREIS, 1990. - $582 \mathrm{p}$.

19. Peuquet, D.J. Introductory Readings in Geographic Information Systems/ D.J. Peuquet, D.F. Marble - London - New York - Philadelphia: Taylor\&Francis., 1990. - 320 p.

20. Raper, J. Three-dimensional Applications in GIS. Taylor\&Francis / J.Raper - London - New York Philadelphia, 1989. - 189 p.

21. Robinson, V.B. Expert systems and geographic information systems: review and prospects / V.B. Robinson, A.U. Frank, M.A. Blaze// Journal of Surveying Engineering, 1986. - vol.112. - №2. - pp.119-130.

22. The 1990 GIS Sourcebook. Geographic Information System Technology in 1990. GIS World, Inc., 1990. - 356 p.

\section{REFERENCES}

1. Berljant A.M. Geoinformacionnoe kartografirovanie [Geographic information mapping]. V kn.: Kartografija i geoinformatika. Itogi nauki i tehniki, ser. Kartografija. M., VINITI AN SSSR, 1991. T.14. Pp.80-117.

2. Ivantsova E.A., Ovcynkin R.V. Komputernoe kartografirovanie soxrannosti zelenyx nasazdeni $\mathrm{v}$ gorodskix landshaftax [Computer mapping of preservation of green spaces in urban landscapes] // Izvestija Nizhnevolzhskogo agrouniversitetskogo kompleksa: Nauka i vysshee obrazovanie [News lower Volga agrodiversity complex: Science and higher education], 2016, no 2 (40), pp. 119-127.

3. Makarov V.Z. i dr. Primenenie GIS-tehnologij pri ocenke faktorov prirodnogo riska na neftjanyh mestorozhdenijah Nizhnego Povolzh'ja [The use of GIS technologies in the assessment of natural risk factors in the oil fields of the Lower Volga region]. GIS-obozrenie, 2004, \#3. Pp.89-98.

4. Nevecherja V.L. Informacionnoe inzhenernogeologicheskoe obespechenie monitoringa slozhnyh prirodno-tehnicheskih sistem (na primere gazovyh promyslov $\mathrm{v}$ kriolitozone) [Information engineering and geological support of monitoring of complex natural and technical systems (on the example of gas fields in the cryolithozone)]. Inzhenernaja geologija, \#1, 1992. Pp. 82-90.

5. Serbenjuk S.N. Kartografija i geoinformatikaih vzaimodejstvie [Cartography and Geoinformatics their interaction]. M., 1990. 159 p.

6. Starcev Ju.P., Shubin M.A. Razrabotka geoinformacionnoj sistemy litomonitoringa gazotransportnogo kompleksa [Development of geographic information system of lythomonitoring of gas transportation complex]. Sb. mat. 3 Vseross. Nauch.-teh. konf. «Vuzovskaja nauka - regionu». Vologda, 2005. Pp. 37-48.

7. Shajtura S.V. Geoinformacionnye sistemy i metody ih sozdanija [Geoinformation systems and methods of their creation]. Kaluga: Izd. N. Bochkarevoj, 1998. 252 p.

8. Shahraman'jan M.A. Novye informacionnye tehnologii $v$ zadachah obespechenija nacional'noj bezopasnosti Rossii (prirodno-tehnogennye aspekty) [New information technologies in the tasks of ensuring national security of Russia (natural and man-made aspects). M., FC VNII GOChS, 2003. 398 p.

9. Sheko A.I., Krupoderov V.S. Vremennoe prognozirovanie jekzogennyh geologicheskih processov [Temporal prediction of exogenous geological processes]. Inzhenernaja geologija, \#3, 1994. Pp. 11-21.

10. Sheko A.I., Krupoderov V.S. Ocenka opasnosti i riska jekzogennyh geologicheskih processov [Hazard and risk assessment of exogenous geological processes]. Inzhenernaja geologija, \#3, 1994. Pp.11-21.

11. Shirjaev E.E. Kartograficheskoe otobrazhenie, preobrazovanie i analiz geoinformacii [Mapping, transformation and analysis of geographic information]. M.: Nedra, 1989. 248 p.

12. Shubin M.A. Metodologicheskie osnovy programmirovanija litomonitoringa [Methodological foundations of programming of lythomonitoring]. Inzhenernaja geologija, 1987, № 6. Pp. 74-86.

13. Shubin M.A. Litomonitoring: teoreticheskie i prikladnye aspekty [Lythomonitoring: theoretical and applied aspects]. Print. Volgograd, 2005. 276 p.

14. Shubin M.A., Jushin O.V. Problemy jekologicheskoj bezopasnosti pribrezhnyh gorodskih territorij Volgogradskogo vodohranilishha [Problems of ecological safety of coastal urban areas of the Volgograd reservoir]. Antropogennaja transformacija geoprostranstva: istorija i sovremennost'. Volgograd : Izd-vo VolGU, 2015. Pp. 416-422.

15. Clarce K.C. Geographic information systems: definitions and prospects. - Bull. Geogr. and Map Div. Spec. Libr. Assoc., 1985, № 142. Pp.12-17. 
16. Ferguson E. Alex. A technical and operational comparison of geographic information systems as applied to the Canada forest industry. Vancouver, FRDA, 1989. $20 \mathrm{p}$.

17. GIS'89 Vancouver, Symposium proceedings “A Wider Perspective", march 7-10 1989, Vancouver, Canada, 1989. 243 p.

18. National Workshop on Geographical Information System, Second, Proceedings. Beijing'90, 8-11 august. Beijing: LREIS, 1990. 582 p.

19. Peuquet D.J., Marble D.F. Introductory Readings in Geographic Information Systems.
Taylor\&Francis. London - New York - Philadelphia, $1990.320 \mathrm{p}$.

20. Raper J. Three-dimensional Applications in GIS. Taylor\&Francis. London - New York Philadelphia, 1989. 189 p.

21. Robinson V.B., Frank A.U., Blaze M.A. Expert systems and geographic information systems: review and prospects. - Journal of Surveying Engineering, 1986, vol.112, № 2. Pp.119-130.

22. The 1990 GIS Sourcebook. Geographic Information System Technology in 1990. GIS World, Inc., $1990.356 \mathrm{p}$.

\section{Information about the Authors}

Mikhail A. Shubin, Doctor of sciences (geology), Professor, Department of Geography and cartography, Volgograd State University, Prosp. Universitetskij, 100, 400062 Volgograd, Russian Federation, gik@volsu.ru.

\section{Информация об авторе}

Михаил Алексеевич Шубин, доктор геолого-минералогических наук, профессор, профессор кафедры географии и картографии, Волгоградский государственный университет, пр. Университетский, 100400062 г. Волгоград, Российская Федерация, gik@volsu.ru. 